\title{
Relationship between Emotional Aspect of Preparatory School Children and their Exposure to Negative Life Experience
}

\author{
Soma Ibrahim Ali, Clinical Instructor \\ Psychiatric Nursing and Mental Health, Faculty of Nursing, Port Said University \\ Samia Mohamed Abd El-Dayem, Professor \\ Psychiatric Nursing and Mental Health, Faculty of Nursing, Alexandria University \\ Hanan Hassan Elezaby, Lecturer \\ Community Health Nursing, Faculty of Nursing, Port Said University \\ Ismaail Mohamed Youssef, Professor \\ Psychiatric Medicine, Faculty of Medicine, Suez Canal University
}

\begin{abstract}
Background: Adolescents of today are the adults of tomorrow. They make significant contributions to the development of the community. Objective: This study is aiming to identify the relationship between emotional aspect of preparatory school children and their exposure to negative life experience. Subjects: The subjects of the study comprised 252 students, 69 of them were males and 183 females, 204 were from Arabic Governmental Schools, and 48 from Experimental Schools, their age ranged from 12 to 15 years. Tools: Five tools were utilized to collect the necessary data in this study. Results: The study revealed that, there is a significant relation between negative life experiences, anxiety and depression. Recommendations: The main recommendations were counseling services for parents and caregivers about how to manage adolescent anxiety and depression related to negative life events and social support should be offered, especially to high-risk families to help them in child rearing.
\end{abstract}

Keywords: Early adolescence, Negative life experience, Anxiety, Depression.

\section{Introduction}

Adolescence is a developmental period characterized by rapid changes in physical, psychological, and social functioning (1) Although many young people pass this developmental period without any problem, there is also many adolescents live in less than nurturing homes, face traumatic events, suffer all types of abuse, become dependent on substance, fear that no one loves or will care for them, think of ways to hurt themselves, and develop illness, such as depression and anxiety (2). 
A negative life events is defined as any event, or negative life changes, directed at oneself or someone else that has caused physical and/or emotional discomfort and require adaptation response ${ }^{(3)}$. Some studies suggest that children in the general population experience between $1.3 \%$ and $7.4 \%$ negative life events over a one-year time period ${ }^{(4)(5)}$.

The main early life negative events are child abuse, parent-child separations, bereavements and divorce. Virtually all of these early life stressors disrupt the child's relationship with their attachment figures ${ }^{(6)}$.

Child abuse, is a type of abuse while consists of any act of commission or omission by a parent or other caregiver that results in harm, potential for harm, or the threat of harm to a child ( 0 -18 years of age) even if the harm is unintentional ${ }^{(7)}$. The four main types of child abuse are: physical , sexual, emotional, and neglect .Physical abuse describes physical injures to a child caused by punches or kicks, shakes or smacks, burns or scalds, drowning or suffocating, bites or poisons ${ }^{(8)}$. Emotional or psychological abuse is designed to control another through use of intimidation, degradation, or fear ${ }^{(9)}$.

Sexual abuse is any form of sexual contact or exposure without consent, or in circumstances in which the victim is incapable of giving consent. Childhood Sexual abuse destroys an individual's positive self-concept and can interfere with the ASNJ Vol.15 No. 2, 2013 learning of self-care skills ${ }^{(10)}$. Child neglect is the failure to provide for a child the basic physical, medical, or educational needs. Examples of child neglect include withholding shelter, adequate nutrition, adequate clothing, access to education, and proper medical or dental care ${ }^{(11)}$.

The impact of father or mother loss is not likely to be diminished by the introduction of stepparents. No one can take away the pain that a child feels when a parent decides to withdraw from his life ${ }^{(12) .}$ The child's response to death of parents varies with age. Meanwhile, teens have increasing understanding of death. They usually become depressed and overactive (13). As suggested by Kazdin (1990), prolonged separation from the mother was a major cause of juvenile delinquency ${ }^{(14)}$. Meanwhile, the effect of separation depends on many factors. These include the age of the child, his previous relationship with his mother, the reason for the separation, the way in which separation was managed and the quality of the new care ${ }^{(13)}$.

Adolescents from divorced families not only deal with the normal developmental stages associated with this age group, but are faced with additional stress placed upon them by their parent's divorce. This includes; inter-parental conflict, economic distress, parent adjustment, multiple life stressors, and short term crises ${ }^{(15) .}$

The main emotional problems which may occur to these adolescents due to their exposure to negative life events are depression and anxiety. Although periods of anxiety or depression during adolescence are common and can be normal reactions to life events, every 
Emotional Aspect of Children and Negative Life Experience

year, approximately 50 in 1000 adolescents

experience the torment of major depression

(16). Adolescent depression is a syndrome that occurs during adolescence years and involves persistent sadness, discouragement, loss of self-worth and loss of interest in usual activities ${ }^{(17) .}$

Anxiety, as a symptom, is a feeling of apprehension caused by anticipation of danger, which may be internal or external. It may be free-floating (pervasive but occurring as an unfocused fear not attached to any idea) or specific and situational. It may be present as fear, which is anxiety caused by consciously recognized and realistic danger, or as agitation, which is severe anxiety associated with motor restlessness ${ }^{(18)}$.

According to Menke (2001), school health nurse play an important role in assessment of each child's stressors and coping behavior when providing care to them. He/she can assist the child in alleviating some stressors by strengthening his coping behavior. Furthermore, the nurse is in an ideal position to help parents and children identify factors that produce stress, and to suggest ways to cope with it's effect. Additionally, parents can meet their basic psychological needs, improve self-esteem, shape values, control exposure to negative events, and provide support ${ }^{(19)}$.

The specific interventions performed by the professional nurses include counseling, case management, providing ASNJ Vol.15 No. 2, 2013 therapeutic milieu and self-care activities, and health teaching (10). Children exposure to negative life events occupies an important position in adolescent's development. So, it was the intent of the present study to explore the relation between negative life events and emotional aspects of adolescents.

\section{Aim of Study}

The aim was to study the relationship between emotional aspect of preparatory school children and their exposure to negative life experience.

\section{$\underline{\text { Research Question: }}$}

1- What are the negative life experiences that are experienced by preparatory school children?

2- What is the relationship between emotional aspect of preparatory school children and their exposure to negative life experience?

\section{Materials and Method}

\section{Materials}

Design: A descriptive correlation research design was used for the current study.

Setting: The study was conducted in three preparatory schools located in Port-Said City namely:

- El-Cana Preparatory governmental Arabic school for Girls representing North zone.

- Mohamed Hafez preparatory governmental Arabic school for boys representing South zone. 
Emotional Aspect of Children and Negative Life Experience

- Mohamed El-Said preparatory experimental English school for boys and girls representing East zone.

Subjects: The subjects of the study comprised 252 students, 69 were males and 183 females, 204 students were from Arabic governmental schools, and 48 students from experimental school, their age ranged from 12 to 15 years.

To ensure that all three zones of port-said governorate are adequately represented in the sample, a multistage stratified cluster random sampling technique was used, in which a sampling frame was developed that includes a list of all the three zones, From each zone one preparatory school was randomly picked up. From each school three classes were randomly picked up, one class from each preparatory level.

Tools: Five tools were used in this study.

Tool I: Socio-Demographic Data questionnaire developed by the researcher to elicit information about demographic variables as age, sex, and family structure in terms of parental presence i.e. with whom the adolescent lives. Also information concerning parents' education and occupation were included.

\section{Tool II: Life Events Scale for Children}

It was developed by Holmes \& Rahe (1967) ${ }^{(20) .}$ It has two compatible Arabic and English version. . The Arabic version was used. It was translated by Abdel-Satar (1996) and assessed for content validity and reliability by the author ${ }^{(21)}$. It include items related to previous negative life events that the child was exposed to as parent death, divorce, physical disability....etc. It consists of 33 negative life events to which the student responds on a 2-point scale (Yes or No). The response is scored "1" if yes or "Zero" if no. The total score is obtained by summing up the scores given to the event in their respective index. These scores were then classified into three grades of life event changes namely mild, moderate, severe proportional to the original scoring system of the total.

\section{Tool III: Child Abuse Questionnaire}

It was developed by Gouda $(2001)^{(22)}$, it is Arabic version and consists of two parts:

Part 1: Developed to assess the occurrence and type of physical abuse. It is composed of 20 questions with graded answers ranging from "never happened" to "occurred for five times or more". Questions probed areas like pushing, slapping, pulling hair, biting, and burning.

Part 2: Developed to assess the occurrence and type of emotional abuse. It contained 15 questions with graded answers similar to that of physical abuse. These questions probed areas such as threatening with knife, cutting hair totally, and panning pocket money.

Regarding validity; it was ascertained by a jury consisting of six experts in the fields of psychiatric nursing, psychiatric medicine, and pediatric nursing. 
Emotional Aspect of Children and Negative Life Experience

Tool IV: The Multidimensional Child and

Adolescent Depression Scale (MCADS):

This scale was developed by AbdelKhalek $(2003)^{(23)}$, it has two compatible Arabic and English version. The Arabic version was used. It was designed to define the profile of child's depression. It has eight dimensions: Pessimism, Weak concentration, Sleep problems, Anhedonia, Fatigue, Loneliness, Low self-esteem, and Somatic complaints. Each dimension is assessed by five statements

A three Likert type rating scale was used to rate the intensity of the depression where None $=1$, Sometimes $=2$, A lot $=3$, except for statements $1,6,11,16,23,34$, and 35 were negatively stated and scored as follow: non 3, sometimes 2 and a lot 1 . Each item should be answered by selecting only one of the three alternatives, which mostly describes the emotional state of the student.

Regarding validity, criterion-related validity ranged between 0.30 and $0.85 \mathrm{With}$ regard to the reliability of the scale, Cronbach alpha ranged from 0.63 to 0.92 while the test-retest reliability ranged between 0.56 and 0.87 .

\section{Tool V: Anxiety Scale for Children. It} was developed by Abdel- Khalek \& ELNayel $\left(1990^{)(24),}\right.$ The scale consists of 21 self descriptive statements to which students respond to a 3-point scale "rare" "sometimes" or "always" according to their perception of the degree that usually suits ASNJ Vol.15 No. 2, 2013 their emotional state. These statements were given a score ranging from 1 to 3 , with 1 donating "rare", 2 donating "sometimes", and 3 donating "always". The total score is obtained by summing up the scores given to the statements in their respective index. The total anxiety score thus ranges between 1 and 63 . With regard to the reliability of the scale; Cronbach alpha ranged from 0.84 to 0.87 .

\section{Method}

\section{Pilot Study}

The pilot study was carried out on $10 \%$ of the subjects represented by 25 students selected randomly from one preparatory school not included in the actual study to test the clarity and applicability of the tools. No modifications carried out on the tools, it was simple and clear for the students. Students completed the study tools within a period of one hour.

\section{Field Work}

The actual study was conducted during the period from first of October 2011 to mid of December 2011, three days each week. Collection of data was performed as the following:

- Before embarking in the fieldwork, the records of the schools number were reviewed. The number of preparatory schools in the three zones was 70 schools. From each zone, one school was selected randomly to represent each zone.

- In each school, the researcher met the headmaster, his/her assistant and the social worker explaining to them the purpose of the 
Emotional Aspect of Children and Negative Life Experience

study and how it will be carried out. Classes from each school were chosen randomly. Students from the three academic levels were represented in the sample.

- The researcher met the students in their classrooms during the break or lots of activities and explained to them the purpose of the study and how to complete the study tools and assured them about the confidentiality of all the data they will provide and that it will be used for research purpose only.

- Each student takes 60-70 minutes in filling the tools.

\section{Ethical Considerations:}

Explanation of the study goal was given to each participant and the rights to refuse or withdraw at any time .Confidentiality of the data was ensured and the collection tools were anonymous.

\section{Statistical Analysis}

Data entry and statistical analysis were done using SPSS 16.0 statistical software package. Data were presented using descriptive statistics in the form of frequencies and percentages for qualitative variables, and means and standard deviations for quantitative variables. Qualitative categorical variables were compared using chi-square test. Whenever the expected values in one or more of the cells in a $2 \times 2$ tables was less than 5, Fisher exact test was used instead. In larger than $2 \times 2$ cross-tables, no test could be applied ASNJ Vol.15 No. 2, 2013 whenever the expected value in $10 \%$ or more of the cells was less than 5. Pearson correlation analysis was used for assessment of the interrelationships among quantitative variables, and Spearman rank correlation for ranked ones. Statistical significance was considered at $\mathrm{p}$ value $<0.5$.

\section{Results}

Table (1) illustrates the socio-demographic characteristics of the studied preparatory school children. The results reveal that almost three quarter of the children $72.6 \%$ were female. More than half of the studied children $53.6 \%$ were in the age group ranging from 12 to 14 years. The mean age was $13.6 \pm 1.0$ years.

It can be noticed that $37.7 \%$ of the studied children were in the grade one. The majority of them $81.0 \%$ were in governmental schools. Speaking about parent's education $10.3 \%$ of fathers and $8.3 \%$ of mothers had university degree. The majority of the studied children 92.4\% were living with their parents compared to $1.6 \%$ of them who lived with their grandparents.

Table (2): demonstrate frequency of life events, physical and emotional abuse as reported by the studied population. It was found that $53.6 \%$ of the children had severe life event risks, whereas only $6.3 \%$ had no life event risks. Regarding physical abuse, it was observed that $37.7 \%$ of the studied children were exposed to physical abuse while $62.3 \%$ were not exposed to physical abuse. 
Emotional Aspect of Children and Negative Life Experience

Speaking about emotional abuse, $21.8 \%$ of those children exposed to this type of abuse but the majority of studied children were not exposed to emotional abuse.

Table (3) demonstrates frequency of anxiety and depression as reported by the studied preparatory school children. It was found that approximately one quarter of the studied children reported severe anxiety while more than one third reported normal anxiety. Concerning depression, it was noticed that only $6.3 \%$ had severe depression and half of those children reported no depression.

Table (4) shows the relation between anxiety, life event risks and depression. It was observed that $35.6 \%$ of children who have been exposed to severe life risks had severe anxiety with statically significant relation between them. The results also show that the majority of the studied children who had severe anxiety had also severe depression with no statically significant relation between them.

Table (5) shows the relation between depression and life event risks. It can be observed that $8.9 \%$ of children exposed to severe negative life events had severe depression with statically significant relation between them.

Table (6) shows correlation matrix of the scores of life events, abuse, anxiety, and depression. It can be noticed that there was significant correlation between negative life events and physical abuse, emotional abuse, anxiety and depression $" \mathrm{r} "=0.408,0.436$, 0.439 , and 0.302 respectively. The table also revealed that there was significant correlation between physical abuse and emotional abuse, anxiety and depression" $\mathrm{r}^{\prime \prime}=0.546,0.420$, and 0.364 respectively. Also, a significant correlation was observed between emotional abuse, anxiety and depression" $r "=0.491$ and 0.487 respectively. The results also showed a significant correlation between anxiety and depression" $\mathrm{r}^{\prime \prime}=0.644$.

\section{Discussion}

The aim of the present research was to study the relation between emotional aspect of preparatory school children and their exposure to negative life experience in order to highlight the consequences of the problem and draw attention to necessary rapid solution. The present study has assessed emotional problems in the form of anxiety and depression among preparatory school children, and their relation with life event changes, and physical \& emotional abuse.

According to the study finding, approximately half of the sample $53.6 \%$ were exposed to severe life events risks, while only $6.3 \%$ of them had no such changes. The most negative events suffered by those adolescents were death of grandparent $(73.0 \%)$, increase in arguments between parents $(30.2 \%)$, and death of close friend (19.4\%). This might be due to more sensitivity of those adolescents to such changes. 
Emotional Aspect of Children and Negative Life Experience

The present study is congruent with what was actually observed by Hassan (2005) (25) who found that $40 \%$ of the adolescents were exposed to severe life event risks and $27.6 \%$ had no such changes. On the other hand, Tohamy \& Mahfouz (2003) have found that the rates were mostly mild life events risks $91.4 \%$, while $8.0 \%$ had moderate risks and only $0.6 \%$ had severe negative life events ${ }^{(26)}$.

The present study shows that $37.7 \%$ of the adolescents were exposed to physical abuse especially in the form of pushing, slapping, pinching, and biting. This may be related to low educational level of parents which leads to decrease awareness about the negative effect of this harsh way in dealing with their adolescents, adding to this the cultural believes of some parents that the punishment is the best way in child-rearing. This is in agreement with the finding of the study done in Canada by Kaur (2008) ${ }^{(27)}$, who reported that more than half of children $58 \%$ were physically abused. Also, Trickatt et al (2009), reported that the incidence of physical abuse among children exposed to maltreatment was $46 \%$, followed by emotional abuse 14\%, and sexual abuse $13 \%^{(28)}$. On the other hand, the present study are incongruent with Gheniam et al. $(2010)^{(29)}$, who studied high school students in Kuwait and found that their experience of physical abuse was only 4.9 $\%$.

ASNJ Vol.15 No. 2, 2013
Speaking about emotional abuse, the present study showed that $21.8 \%$ of the studied adolescents were exposed to emotional abuse. This may be related to that the majority of the studied adolescents were female, and by nature they are very sensitive to negative words used by the parents.

In another study Trickatt et al. (2009) (28) found that $50 \%$ of the respondents in their survey suffered from emotional abuse. Also, in this regard Gouda (2001), did a study on primary school children in port-said and found that emotional abuse came second to physical abuse with a percentage of $26 \%{ }^{(22)}$.

Regarding anxiety, the present study indicated that, approximately one quarter of the study subjects had severe anxiety while $31.7 \%$ had mild-moderate anxiety and $42.9 \%$ had normal anxiety.

Speaking about depression, the present study revealed that half of the studied children were free from depression comparing with only $6.3 \%$ of them had severe depression. The result of the present study is supported by Saad (2007) who documented that teens who suffering from depression were $18.1 \%$ while $81.9 \%$ not suffering from depression ${ }^{(30)}$.

The present study assessed emotional problems in the form of anxiety and depression among adolescents, and their relation with life event risks. According to the study finding, a statically significant relation was found between life event risks and anxiety. This may be due to feelings associated with the beginning of adolescence and stress accompanying this stage 
Emotional Aspect of Children and Negative Life Experience

which make adolescents more anxious. The present result is in agreement with Garber (2006), who found that adolescent's exposure to stressful life events is associated with increase symptoms of anxiety $^{(31)}$.

In other words, negative life event scores were independent predictors of anxiety scores (25) (32). While, Mark (2008) found that there is no significant relation between life stressors and anxiety onset ${ }^{(33)}$.

Results of the present study found that life event changes had significant relation with depression and this may be because $26.7 \%$ of the studied adolescents suffer from absence of parents, whether in the form of death, divorce, another marriage and traveling which lead to absence of warm, parental figure with whom to identify, and sense of emotional and social isolation. Absence of parents leads to lack of emotional support when needed and it is harder on the adolescents to be deprived from the affection of one of his parents. Emotionally adolescents become very much insecure, and this insecurity can be a cause of their depression.

Several reviews concluded that stressful life events are associated with depression, especially first episodes of depression ${ }^{(34,35)}$. On the other hand, this was completely in opposition with Truss (2008) who carried a study on primary school children in U.S.A and reported that ASNJ Vol.15 No. 2, 2013 there is no relation between negative life events and depressive symptoms ${ }^{(36)}$.

The present study revealed a significant correlation between life event risks and physical abuse, emotional abuse, anxiety, and depression. This is supported by the finding of Gheniam et al. (2010) who revealed that the correlation between the total physical/emotional scores and anxiety and depression scores were all positive and highly significant ${ }^{(29)}$.

Regarding the correlation between anxiety and depression, the present study revealed that anxiety as a clinical state had significant correlation with depression. This is in accordance with Saad (2007) who revealed in her study on teens that there is high correlation between anxiety and depression ${ }^{(30)}$. Moreover, these finding are also consistent with Aly et al. (2006) who mentioned that among their depressed children $95.5 \%$ of them had anxiety $^{(37)}$, and Joy (2003) who found that there was a strong correlation overall between anxiety and depression scores for his sample population.

\section{Conclusion}

From findings of this study, it is concluded that:

Exposure to negative life events may lead to anxiety and depression. Furthermore, there were positive correlation between life event risks and physical abuse, emotional abuse, anxiety and depression. 
Emotional Aspect of Children and Negative Life Experience

\section{Recommendations}

In the light of the findings of this study, the following is recommended

1- The school nurses need to be trained to assess the psychological status of the school children and in counseling about adaptation and coping strategies.

2- Health education program must be prepared for the parents and their adolescent about how to cope with stressful life events.
3- Counseling services for parents and caregivers about adolescent care, physically, emotionally, and socially and how to manage adolescent anxiety and depression related to negative life events.

4- Social support should be offered, especially to high-risk families to help them in child rearing. 
Table (1): Socio-demographic characteristics of the studied preparatory school children

\begin{tabular}{|c|c|c|}
\hline & $\begin{array}{l}\text { Frequency } \\
\mathrm{N}=\mathbf{2 5 2}\end{array}$ & Percent \\
\hline $\begin{array}{l}\text { Sex: } \\
\text { Male } \\
\text { Female } \\
\end{array}$ & $\begin{array}{l}69 \\
183 \\
\end{array}$ & $\begin{array}{l}27.4 \\
72.6 \\
\end{array}$ \\
\hline $\begin{array}{l}\text { Age (years): } \\
12<14 \\
14+ \\
\text { Range } \\
\text { Mean } \pm \text { SD } \\
\end{array}$ & $\begin{array}{l}135 \\
117 \\
12-16 \\
13.6 \pm 1.0 \\
\end{array}$ & $\begin{array}{l}53.6 \\
46.4\end{array}$ \\
\hline $\begin{array}{l}\text { School grade: } \\
1 \\
2 \\
3 \\
\end{array}$ & $\begin{array}{l}95 \\
72 \\
85 \\
\end{array}$ & $\begin{array}{l}37.7 \\
28.6 \\
\quad 33.7 \\
\end{array}$ \\
\hline $\begin{array}{l}\text { School type: } \\
\text { Governmental } \\
\text { Experimental } \\
\text { Birth order: } \\
1 \\
2 \\
3+ \\
\end{array}$ & $\begin{array}{l}204 \\
48 \\
94 \\
87 \\
71 \\
\end{array}$ & $\begin{array}{l}81.0 \\
19.0 \\
\\
37.3 \\
34.5 \\
28.2 \\
\end{array}$ \\
\hline $\begin{array}{l}\text { Father education: } \\
\text { Illiterate } \\
\text { Read/write } \\
\text { Basic } \\
\text { Intermediate } \\
\text { University } \\
\end{array}$ & $\begin{array}{l}23 \\
34 \\
44 \\
125 \\
26 \\
\end{array}$ & $\begin{array}{l}9.1 \\
13.5 \\
17.5 \\
49.6 \\
10.3 \\
\end{array}$ \\
\hline $\begin{array}{l}\text { Mother education: } \\
\text { Illiterate } \\
\text { Read/write } \\
\text { Basic } \\
\text { Intermediate } \\
\text { University }\end{array}$ & $\begin{array}{l}28 \\
27 \\
79 \\
97 \\
21\end{array}$ & $\begin{array}{l}11.2 \\
10.7 \\
31.3 \\
38.5 \\
8.3\end{array}$ \\
\hline $\begin{array}{l}\text { Father job: } \\
\text { Unemployed/retired } \\
\text { Employee } \\
\text { Manual worker } \\
\end{array}$ & $\begin{array}{l}14 \\
124 \\
114 \\
\end{array}$ & $\begin{array}{l}5.6 \\
49.2 \\
45.2 \\
\end{array}$ \\
\hline $\begin{array}{l}\text { Mother job: } \\
\text { Housewife } \\
\text { Working } \\
\end{array}$ & $\begin{array}{l}157 \\
95 \\
\end{array}$ & $\begin{array}{l}62.3 \\
37.7 \\
\end{array}$ \\
\hline $\begin{array}{l}\text { Live with: } \\
\text { Family (complete) } \\
\text { Father } \\
\text { Mother } \\
\text { Grandparents } \\
\end{array}$ & $\begin{array}{l}233 \\
7 \\
8 \\
4 \\
\end{array}$ & $\begin{array}{l}92.4 \\
2.8 \\
3.2 \\
1.6 \\
\end{array}$ \\
\hline
\end{tabular}


Table (2): Life events, physical and emotional abuse as reported by the studied preparatory school children.

\begin{tabular}{|l|l|l||}
\hline Life event risks, physical abuse, emotional abuse & Frequency & Percent \\
\hline Life events risk: & 16 & 6.3 \\
None & 101 & 40.1 \\
Mild/moderate & 135 & 53.6 \\
severe & & \\
\hline Physical abuse: & 157 & 62.3 \\
None & 95 & 37.7 \\
Exposed to & & 78.2 \\
\hline Emotional abuse: & 197 & 21.8 \\
None & 55 & \\
Exposed to & 5 & \\
\hline
\end{tabular}

Table (3): Frequency of anxiety and depression as reported by the studied preparatory school children

\begin{tabular}{||l|l|l|}
\hline \multicolumn{1}{|c|}{ Anxiety and depression } & Frequency & Percent \\
\hline Anxiety: & 108 & \\
None & 80 & 42.9 \\
Mild/moderate & 64 & 31.7 \\
Severe & & 25.4 \\
\hline Depression: & 126 & \\
None & 110 & 50.0 \\
Mild/moderate & 16 & 43.7 \\
Severe & & 6.3 \\
\hline \hline
\end{tabular}


Emotional Aspect of Children and Negative Life Experience

Table (4): Relation between anxiety, life event risks, and depression among the studied preparatory school children.

\begin{tabular}{|c|c|c|c|c|c|c|c|c|}
\hline & Anx & & & & & & & \\
\hline & Non & & Milc & nod & Seve & & & p-value \\
\hline & No. & $\%$ & No. & $\%$ & No. & $\%$ & & \\
\hline Life events risk: & & & & & & & & \\
\hline None & 10 & 62.5 & 6 & 37.5 & 0 & 0.0 & & \\
\hline Mild/moderate & 52 & 51.5 & 33 & 32.7 & 126 & 15.8 & 19.08 & $<0.001 *$ \\
\hline Severe & 46 & 34.1 & 41 & 30.4 & 48 & 35.6 & & \\
\hline Depression: & & & & & & & & \\
\hline None & 87 & 69.0 & 32 & 25.4 & 7 & 5.6 & & \\
\hline Mild/moderate & 19 & 17.3 & 47 & 42.7 & 44 & 40.0 & -- & -- \\
\hline Severe & 2 & 12.5 & 1 & 6.3 & 13 & 81.3 & & \\
\hline
\end{tabular}

Table (5): Relation between depression and life event risk among the studied preparatory school children.

\begin{tabular}{|c|c|c|c|c|c|c|c|c|}
\hline & \multicolumn{6}{|c|}{ Depression } & \multirow{3}{*}{$\begin{array}{l}\mathrm{X}^{2} \\
\text { Test }\end{array}$} & \multirow{3}{*}{ p-value } \\
\hline & \multicolumn{2}{|c|}{\begin{tabular}{|l|} 
None \\
\end{tabular}} & \multicolumn{2}{|c|}{ Mild/mod } & \multicolumn{2}{|c|}{ Severe } & & \\
\hline & No. & $\%$ & No. & $\%$ & No. & $\%$ & & \\
\hline Life events risk: & & & & & & & & \\
\hline None & 8 & 50.0 & 7 & 43.8 & 1 & 6.3 & & \\
\hline Mild/moderate & 61 & 60.4 & 37 & 36.6 & 3 & 3.0 & 9.59 & $0.005^{*}$ \\
\hline severe & 57 & 42.2 & 66 & 48.9 & 12 & 8.9 & & \\
\hline
\end{tabular}

Table (6): Correlation matrix of the scores of life events, abuse, anxiety, and depression among the studied preparatory school children

\begin{tabular}{|c|c|c|c|c|c|}
\hline \multirow{3}{*}{ Scores of } & \multicolumn{5}{|c|}{ Pearson correlation coefficients $(r)$} \\
\hline & \multicolumn{5}{|c|}{ Scores of } \\
\hline & $\begin{array}{l}\text { Life } \\
\text { events }\end{array}$ & $\begin{array}{l}\text { Physical } \\
\text { Abuse }\end{array}$ & $\begin{array}{l}\text { Emotional } \\
\text { Abuse }\end{array}$ & Anxiety & Depression \\
\hline Life events & 1 & & & & \\
\hline Physical abuse & $0.408^{* *}$ & 1 & & & \\
\hline Emotional abuse & $0.436^{* *}$ & $0.546^{* *}$ & 1 & & \\
\hline Anxiety & $0.439^{* *}$ & $0.420^{* *}$ & $0.491^{* *}$ & 1 & \\
\hline Depression & $0.302^{* *}$ & $0.364^{* *}$ & $0.487^{* *}$ & $0.644^{* *}$ & 1 \\
\hline
\end{tabular}


Emotional Aspect of Children and Negative Life Experience

\section{References}

1. Kim H. Correlation of the health problems with psychological construct in adolescents: Final results from a 2-years study. International Journal of Nursing Studies;2003, 40; 115-24.

2. Cannon P. and Frank D. Promoting ego development and multicultural competence during internship. International Journal of Advanced Counseling; 2009, 31, 199-211.

3. Shannon S. Carothers G. and Thomas L . Children of Adolescent Mothers Elsevier. Philadelphia; 2006, 716-36.

4. Lengua J. and Long C. The role of emotionality and self-regulation in the appraisal-coping process: tests of direct and moderating effects. Applied Developmental Psychology; 2002, 23, 471-93.

5. Reinemann S. and Ellison T. The applicability of cognitive models to explain Children's Depression Inventory Factor Scores in urban youth. School Psychology Quarterly; 2004,19, 231-52.

6. Carr A. The Handbook of Child and Adolescent Clinical Psychology. London: Routledge; 1999, 35-42, 56-62.

7. Hahm H. Lee Y., Ozonoff A. and Wert V. The Impact of Multiple Types of Child Maltreatment on Subsequent Risk Behaviours among Women during the Transition from Adolescence to Young Adulthood. American journal of psychiatry; 2009, 39: 528-40.

ASNJ Vol.15 No. 2, 2013
8. Howe C. Jawad A. Kelly S. and Lipman T. Weight-related concerns and behaviors in children and adolescents with type1 diabetes. Journal of the American Psychiatric Nurses Association; 2008, 13(6): 376 - 85.

9. Antai-Otong D. Psychiatric nursing: biological and behavioral concepts, $2^{\text {nd }}$ edition. Delmar. Thomson co, 2008, 762.

10. Mash E., Carson V. and Shoemaker N. Foundations of Psychiatric mental health nursing, $5^{\text {th }}$ edition. Elsevier. Saunders co, Philadelphia, USA; 2006, 510-14.

11. Shives L. Basic concepts of psychiatric mental health nursing, $7^{\text {th }}$ edition. Philadelphia, PA, Lippincott Williams and Wilkins. Crawfordville co; 2008, 640.

12. Caron Z., Keller S. and Martin E. Psychological and Emotional Aspects of Divorce. Journal of Consulting and Clinical Psychology, Retrieved June 1997.

13. Blackman J. AttentionDeficit/Hyperactivity Disorder in Preschoolers. Pediatric Clinics in North America; 2000, 46(5): 1011-45.

14. Kazdin A. Childhood Depression. Journal of child Psychology and Psychiatry and Allied Disciptincy; 1990, 31: 121-61.

15. Thompson P. Adolescents from families of divorce: vulnerability to physiological and psychological disturbances. Journal of psychosocial nursing; 1998, 36 (3): 34-9. 
Emotional Aspect of Children and Negative Life Experience

16. William M., Russell I., Crane C., Russell D., Whitaker C., Danielle D., Barnhofer T., Fennell M. and Silverton S. Staying well after depression: Trail design and protocol. BMC Psychiatry, 2010, 10 (23).

17. Agerter D., Rasmussen N. and Sutor B. (2007): Depression in Rakel. Text book of family medicine. $7^{\text {th }}$ ed., Saunders El servier. Philadelphia; 2007, 1081-9.

18. Fainman D. Examining the relationship between anxiety disorders and depression. Journal of psychiatry. 2004, 18(2): 568- 70.

19. Menke M. School- age children's stressors and coping behavior, Journal of pediatric nursing; 2001, 102-6.

20. Holmes T. and Rahe R. The Social Readjustment Rating Scale. Journal of Psychosomatic Research; 1967, 11(2): 21318.

21. Abdel- Satar I. Relation between stressful life events and aggressive behavior in children .unpublished Master thesis, faculty of nursing, Zagazig University, 1996, 57 66.

22. Gouda S. Impact of physical and emotional abuse on primary school children in port said city. Unpublished Master Thesis. Faculty of Nursing. Port said university, 2001, 54-96.

23. Abdel-Khalek A. The multi-Dimensional Child and Adolescent Depression Scale: Psychometric Properties. Psychological Reports; 2003, 93: 544-60.
24. Abdel Khalek A. and El Nayel M. Anxiety Scale for Children and Relation it and Psychological Disturbance. Journal of Psychology; 1990, 1(18): 38-40.

25. Hassan R. Effect of negative life events on emotional and behavioral aspects of preparatory school children in Ismailia. Unpublished Master Thesis. Faculty of nursing. Ain-Shams University; 2005, 75120.

26. Tohamy S. and Mahfouz R. Violence among children and adolescent. Child Mental Health Association, Eastern Mediterranean Association for children and adolescent. Mars; 2003,131 (3): 217-20.

27. Kaur P: A framework for understanding the relation between childhood maltreatment and adult suicidal action. Unpublished Doctoral Dissertation. Department of Psychology. Canada; 2008. 116-29.

28. Trickatt P, Kim C, Sang G. Emotional abuse in a sample of multiply maltreated urban young adolescents. Child abuse and neglect. Unpublished Doctoral Dissertation, 2009. 27-35.

29. Gheniam W. Rasmussen N. and Sutor B. Prevalence of physical, psychological, and sexual abuse among a nationwide sample of Arab high school students: association with family characteristics, anxiety, depression, self-esteem, and quality of life. Kuwait. 2010, 47(1):53-66. 
Emotional Aspect of Children and Negative Life Experience

30. Saad A. Depression Profile among Teenagers in Alexandria Governorate. Unpublished Doctoral Dissertation. Alexandria University. Faculty of nursing; 2007, 1 - 9 .

31. Garber J. "Depression in children and adolescents: linking risk research and prevention." Am J Prev Med 31 (6 Suppl 1): 2006, S104-25.

32. Gothelf D., Aharonovsky O., Horesh N., Carty T. and Apter A. Life events and personality factors in children with Obsessive-Compulsive Disorder and other anxiety disorders. Comprehensive Psychiatry; 2004, 45, 192-8.

33. Marks M. Introductory Pediatric Nursing, $4^{\text {th }}$ ed. Philadelphia: Lippincott; 2010, 33040.

34. Hagen R. Assessing the diathesis-stress model of adolescent depression in 9- to 14- year-old girls: The combined effect of stressful life events and negative selfschema. United States; 2007, 161.

35. Jones R. Group treatment of sexually abused adolescent girls: A review of outcome study. The American journal of family therapy; 2007, 315-26.

36. Truss A. A competency-based model of depression in children: self-perceived competence as a mediator of the relations of parenting and negative life events to depressive symptoms. Unpublished Doctoral Dissertation. Department of Psychology. U.S.A; 2008, 30-2.

37. Aly N., Hassan S., Mohamed R., ElSamman G., Ahmed E., Gomiaa H., and El Guindy S. Health profile of Egyptian school adolescents in Cairo and Giza Governorates. The new Egyptian journal of medicine; 2006, 34: 1-29. 